\title{
EXPERIMENTAL STUDY OF HEAT TRANSFER AND PRESSURE DROP IN MECHANICALLY-ASSISTED HEAT EXCHANGERS WITH ACTIVE SCRAPERS
}

\author{
$\underline{\text { J P Solano }}^{1}$, A García ${ }^{1}$, P G Vicente ${ }^{2}$, A Viedma ${ }^{1}$ \\ ${ }^{1}$ Departamento de Ingeniería Térmica y de Fluidos, Universidad Politécnica de Cartagena. \\ Campus de la Muralla del Mar, 30202 Cartagena, Spain. \\ Tel: +34 96832 5938, Fax: +34 96832 5999, e-mail address: juanp.solano@upct.es \\ ${ }^{2}$ Departamento de Ingeniería de Sistemas Industriales, Universidad Miguel Hernández. \\ Avenida del Ferrocarril, s/n, 03202 Elche, Spain.
}

\begin{abstract}
A mechanically assisted heat exchanger has been studied. The reciprocating movement of the active insert device, located inside a round tube, generates macroscopic displacements of the flow, increasing heat transfer. At the same time, the inner tube wall scraping avoids fouling. Pressure drop and heat transfer characteristics have been experimentally studied, in order to characterize the thermo-hydraulic behaviour of the dynamic insert device, using propylene-glycol as working fluid. Experimental results for Fanning friction factor and Nusselt number as functions of flow and dimensionless geometric parameters have been presented.

Friction factor increases up to two times at higher Reynolds numbers for different scraping frequencies. Nusselt number increases up to four times at low Reynolds numbers, for different scraping frequencies. At high Reynolds number, no influence of the scraping frequency is shown.
\end{abstract}

\section{Nomenclature}

A free transversal area, $\pi\left(D^{2}-d^{2}\right),\left(\mathrm{m}^{2}\right)$

$c_{p} \quad$ specific heat $\left(\mathrm{J} \cdot \mathrm{kg}^{-1} \mathrm{~K}^{-1}\right)$

$D \quad$ maximum inner diameter (m)

$D_{h} \quad$ hydraulic diameter, $D-d,(\mathrm{~m})$

$d \quad$ shaft diameter (minimum inner) (m)

$p \quad$ pitch of the insert devices (m)

$h \quad$ heat transfer coefficient $\left(\mathrm{W} \cdot \mathrm{m}^{-2} \mathrm{~K}^{-1}\right)$

I electric current (A)

$k \quad$ thermal conductivity $\left(\mathrm{W} \cdot \mathrm{m}^{-1} \mathrm{~K}^{-1}\right)$

$L_{p} \quad$ length between pressure taps (m)

$L_{h} \quad$ length of the heat transfer section (m)

$\dot{m} \quad$ mass flow rate $\left(\mathrm{kg} \cdot \mathrm{s}^{-1}\right)$

$\overline{\Delta P} \quad$ time averaged pressure $(\mathrm{Pa})$

$Q \quad$ overall electrical power added (W)

$Q_{1} \quad$ heat losses in the test section (W)

$q^{\prime \prime} \quad$ heat flux $\left(Q-Q_{1}\right) / \pi D l_{h}\left(\mathrm{~W} \cdot \mathrm{m}^{-2}\right)$

$t$ temperature (K)

$s \quad$ movement amplitude (m)

$\bar{t}_{w i} \quad$ average inside tube wall temp. (K)

$\bar{t}_{\text {wo }}$ average outside tube wall temp. (K)

$\begin{array}{ll}V & \text { voltage }(\mathrm{V}) \\ \dot{V} & \text { volumetric flow-rate }\left(\mathrm{m}^{3} / \mathrm{s}\right) \\ \bar{v}_{f} & \text { mean fluid velocity, } \dot{V} / A_{t}(\mathrm{~m} / \mathrm{s}) \\ x_{p} & \text { measuring point axial position }(\mathrm{m})\end{array}$

Dimensionless groups

$f_{D h} \quad$ Fanning friction factor

$\mathrm{Nu} \quad$ Nusselt number, $h \mathrm{D} / \mathrm{k}$

$\operatorname{Pr} \quad$ Prandtl number, $\mu c_{p} / k$

Sr Strouhal number, $s \omega / \bar{v}_{f}$

$R e_{D h} \quad$ Reynolds number, $\rho \bar{v}_{f} D_{h} / \mu$

Greek symbols

$\mu \quad$ dynamic viscosity (Pa.s)

$\omega \quad$ movement frequency $\left(\mathrm{s}^{-1}\right)$

$\rho \quad$ fluid density $\left(\mathrm{kg} \cdot \mathrm{m}^{-3}\right)$

Subscripts

b based on bulk temperature

in tube inlet

out tube outlet

w based on inside wall temperature 


\section{Introduction}

Heat transfer processes in the food and chemical industries frequently deal with highly viscous liquids. The performance of heat exchangers working under these conditions is usually low, as a result of the characteristics of the encountered laminar regime (Webb, [1]). Moreover, the heat transfer surfaces may become coated with a deposit of solid material after a period of operation. This phenomenon, known as fouling, causes a reduced overall heat transfer coefficient (Bergles, [2]).

Heat exchangers are generally over-designed to compensate for the anticipated fouling (Webb, [1]). Moreover, cleaning operations decrease equipment availability, which causes as well a considerable economic impact.

Mechanically assisted heat exchangers, where a heat transfer surface is periodically scraped by a moving element, might be used to avoid the problems caused by fouling. Equipment with rotating scraping blades are found in commercial practice: they prevent fouling and promote mixing and heat transfer. Many investigations have focused on these anti-fouling devices, studying flow pattern characteristics (Wang et al, [3]), their thermo-hydraulic performance (Goede and Jong, [4]) or scraping efficiency (Sun et al, [5]).

This work presents the study of a dynamic insert device moved alternatively along the axial direction by a hydraulic cylinder. The active insert device is made up of several semi-circular elements, which are mounted on a shaft with a pitch of 5D (Fig. 1). When inserted inside the tube, the device produces a double effect: the induced flow generates macroscopic displacements from the boundary layer region to the axis of the tube, increasing heat transfer, and the elements with reciprocating movement scrape the inner tube-wall, avoiding fouling.

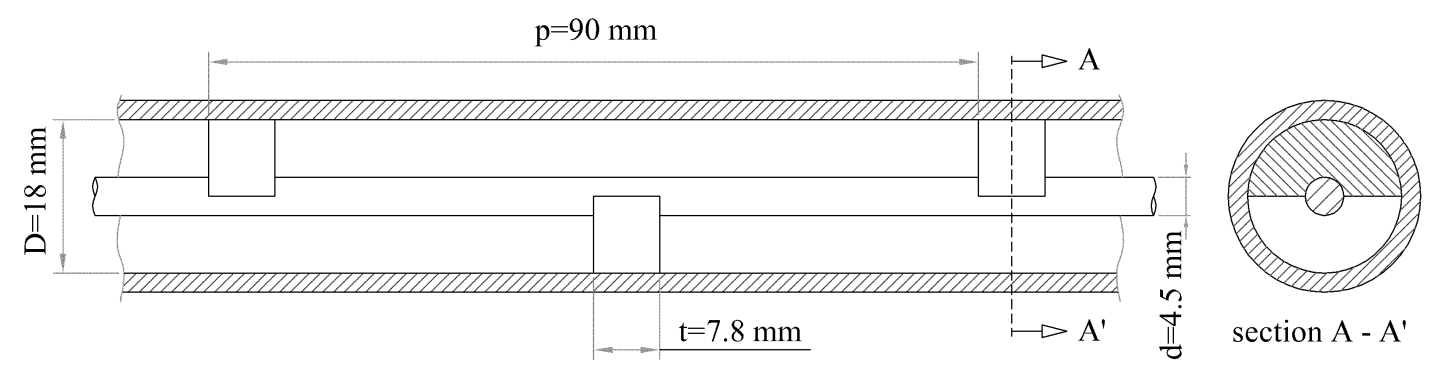

Figure 1. Sketch of the active device

There is empirical evidence of the heat transfer enhancement and fouling prevention of this kind of active devices. However, the authors have not found in the open literature previous works related to this type of mechanically-assisted heat exchangers.

This work presents an experimental study on the pressure drop and heat transfer characteristics of the active insert device depicted in Fig. 1. Experimental results of Fanning friction factor $f$ and Nusselt number $\mathrm{Nu}$ as functions of flow parameters and scraping frequency are provided for laminar flow. 


\section{Experimental setup}

A schematic diagram of the experimental setup is shown in Fig. 2. It consists of two independent circuits: the main circuit, where the dynamic insert device was installed, and the secondary circuit which was used for regulating the tank temperature to a desirable value. All the instrumentation was connected to a HP 34970A Data Acquisition Unit.

Heat transfer experiments were carried out under uniform heat flux conditions, where energy was added to the working fluid by Joule effect heating. A $6 \mathrm{kVA}$ transformer was connected to the smooth tube by copper electrodes and power supply was regulated by means of an auto-transformer. The length between electrodes defined the heat transfer test section $\left(L_{h}=1.10 \mathrm{~m}\right)$. To reduce heat losses, this section was coated with a thermal insulation of $20 \mathrm{~mm}$ thickness and thermal conductivity $0.04 \mathrm{~W} / \mathrm{mK}$. The overall electrical power added to the heating section, $Q$, was calculated by measuring the voltage between electrodes $(0-15 \mathrm{~V})$ and the electrical current (0600A).

The reciprocating movement of the inserted scraper is achieved by means of a hydraulic unit. This unit moves linearly a cylinder over which the shaft of the insert device is mounted. Two relays are positioned at an adjustable distance, which is a function of the desired movement amplitude and frequency. When the end of the piston presses one relay, it drives the internal open/close valves of the hydraulic unit, and the movement of the piston reverses. In the tests carried out at the present work, the relays have been positioned in order to obtain a movement amplitude equals to the pitch of the active device $(s=p=90 \mathrm{~mm})$.

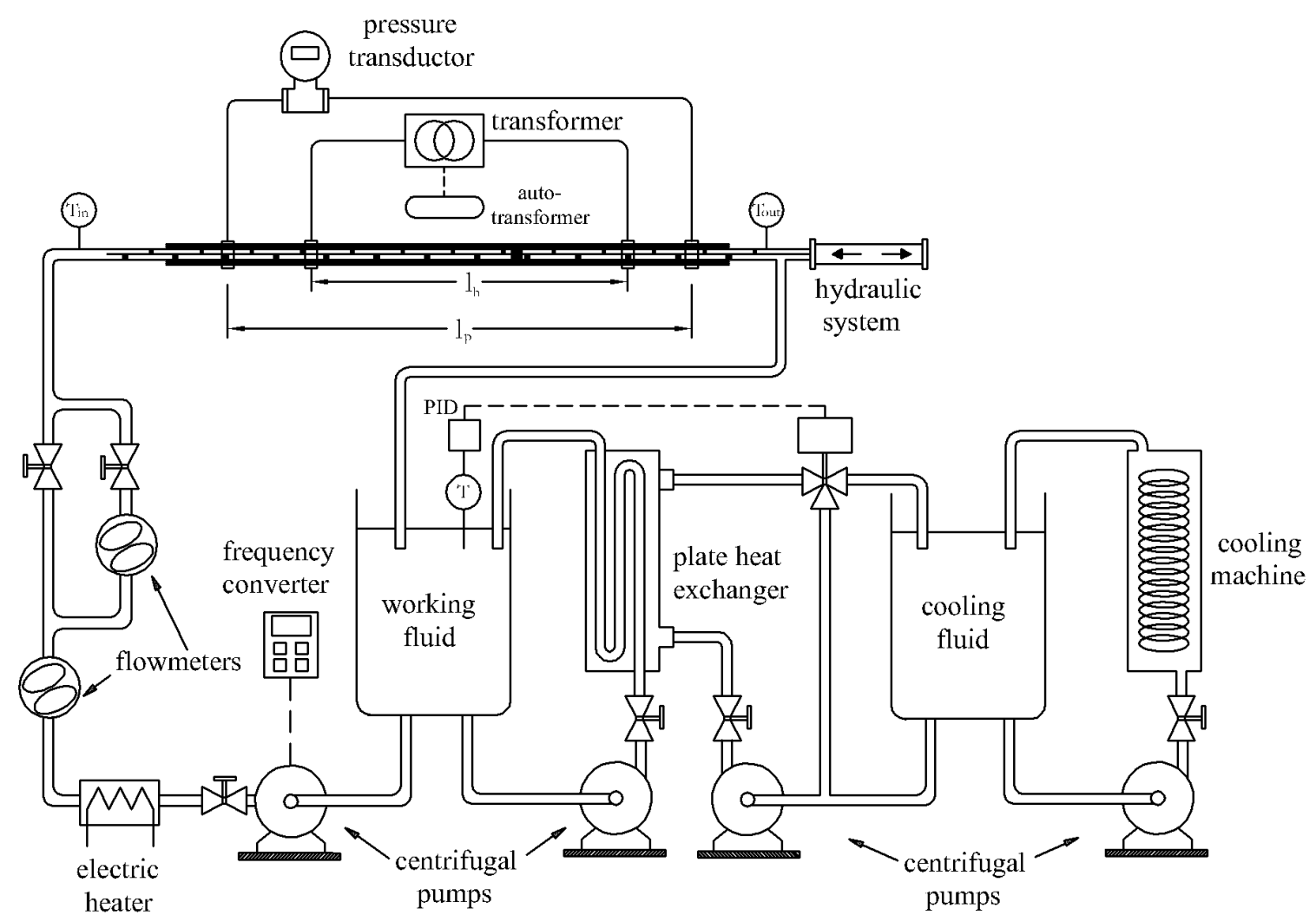

Figure 2. Experimental setup 
Fluid inlet and outlet temperatures, $t_{\text {in }}$ and $t_{\text {out }}$ were measured by submerged type resistance temperature detectors (RTDs). Since heat was added uniformly along the tube length, the bulk temperature of the fluid at the measuring section, $t_{b}\left(x_{p}\right)$, was calculated by considering a linear variation with the axial direction. Average outside surface temperature of the wall $\bar{t}_{w o}$ was measured at two different axial positions $x_{p}$, located at 50 and 52 diameters from the upstream electrode, that ensure fully developed flow. The value of $\bar{t}_{\text {wo }}$ was calculated by averaging the temperatures measured with eight surface type RTDs peripherally spaced by every $45^{\circ}$ at one axial position. Data reduction with experimental measurements at both axial positions revealed similar heat transfer results.

The RTD naked sensors were wrapped with ultra-thin plastic films, which assured electrical isolation. The low thickness of the film makes its thermal resistance negligible. A highly thermalconductive paste was spread between the tube wall and the wrapped RTD sensor. Each temperature value used for data reduction was averaged over 30 data sampled every 20 seconds.

Two calibration tests with no electrical heating were done: the first test was performed to determine heat losses in the test section $Q_{1}$ by measuring $\left(t_{\text {in }}-t_{\text {out }}\right)$ at low flow rates, and the second test at high flow rates to calculate the lay-out resistances of the surface type RTDs $\left(t_{\text {in }} \approx t_{\text {out }} \approx \bar{t}_{\text {wo }}\right)$.

Heat flux added to the test fluid $q$ " is calculated by subtracting heat losses to the overall electrical power added in the test section. The power factor was 1.0, as expected from the fact that the copper electrodes were directly connected to the metallic tube, which is a pure resistive load. The inner wall temperature $\bar{t}_{w i}$ for each experimental point, was determined by using a numerical model that solves the steady-state, one dimensional, radial, heat conduction equation in the tube wall and insulation from the following input data: $\bar{t}_{w o}, Q, Q_{1}$ and $t_{b}\left(x_{p}\right)$. The local Nusselt number was calculated by means of

$N u_{x}=\frac{D}{k} \frac{q^{\prime \prime}}{\bar{t}_{w i}-t_{b}\left(x_{p}\right)}$

In insert devices, even for low Reynolds numbers, flow is fully developed at few pitches (2-3 $p$ ). The local Nusselt number was calculated at $x / D \approx 50$ and therefore this is the asymptotic Nusselt number. Thus, it can be assumed that Eq (1) provides approximately the mean Nusselt number. Nusselt number values computed with Eq. (1) were corrected by the factor $\left(\mu_{w} / \mu_{b}\right)^{0.14}$ to obtain correlations free of variable properties effects.

Pressure drop tests were carried out in the hydro-dynamically developed region under isothermal conditions. The hydraulic diameter $D_{h}=D-d$ was used as the reference diameter to calculate all friction factors. It takes account of the presence of the shaft inside the tube, but does not consider the effect of the plugs mounted on it. Fanning coefficients $f_{D h}$ were determined from fluid mass flow rate and pressure drop measurements by means of

$$
f_{D h}=\frac{D_{h}}{L_{p}} \frac{\overline{\Delta P}}{2 \rho \bar{v}_{f}}
$$


Pressure drop $\overline{\Delta P}$ was measured along the pressure test section $\left(L_{p}=2.83 \mathrm{~m}\right)$ by means of a highly accurate pressure transducer. Four pressure taps separated by $90^{\circ}$ were coupled to each end of the pressure test section. Two differential pressure transducers of different full scales assured the accuracy of the experiments. The alternative movement of the scraper generated a transient differential pressure along the test section. To obtain the mean pressure drop over a scraper cycle, an integration of the instantaneous signal over a sufficient time interval was performed in the pressure transducer.

The experimental uncertainty was calculated by following the "Guide to the expression of uncertainty in measurement" published by ISO [6]. Details of the uncertainty assignation to the experimental data are given by the authors in [7]. Uncertainty calculations based on a 95\% confidence level showed maximum values of $4 \%$ for Reynolds number, 3.5\% for Prandtl number, $6 \%$ for Nusselt number and 3\% for friction factor.

\section{Experimental Results}

An experimental research was carried out to characterize the thermo-hydraulic behaviour of the dynamic insert device sketched in Fig. 1. Experiments were carried out employing propylene glycol at 15,25 and $40^{\circ} \mathrm{C}$, with flow rates from 100 to 1000 liters/h and movement frequencies from 0.25 to 2 cycles per second. The amplitude of the scraper movement was $90 \mathrm{~mm}$, which fits its geometrical pitch. A large range of flow conditions, non-dimensionalized by Reynolds, Prandtl and Strouhal numbers, was achieved.

\subsection{Pressure Drop Results}

Pressure drop tests were carried out under isothermal conditions covering a wide range of flow conditions: Reynolds numbers from 25 to 900 and Strouhal numbers from 0 (static) to 1.6. Experimental data are presented in terms of Fanning friction factor versus Reynolds number. Strouhal number, defined as $S r=s \cdot \omega / \bar{v}_{f}$, was found to be an excellent non-dimensional parameter to evaluate dynamic effects. Fanning friction factor results are presented in Fig. 3.

Results show that at Strouhal numbers below 0.5, the flow may be considered to be stationary and friction factor results depend only on Reynolds number. Friction factor results for the static $(\omega=0)$ insert device have been correlated by

$$
\begin{gathered}
f_{D h}=11.2 R e_{D h}^{-0.66} \quad\left(R e_{D h}<150\right) \\
f_{D h}=2.21 R e_{D h}^{-0.31} \quad\left(R e_{D h}>150\right)
\end{gathered}
$$

Friction factor results at dynamic conditions for Strouhal numbers above 0.5 have been correlated by

$$
f_{D h}=6.14 R e_{D h}{ }^{-0.36} S r^{0.64} \quad\left(R e_{D h}<500, S r>0.5\right)
$$




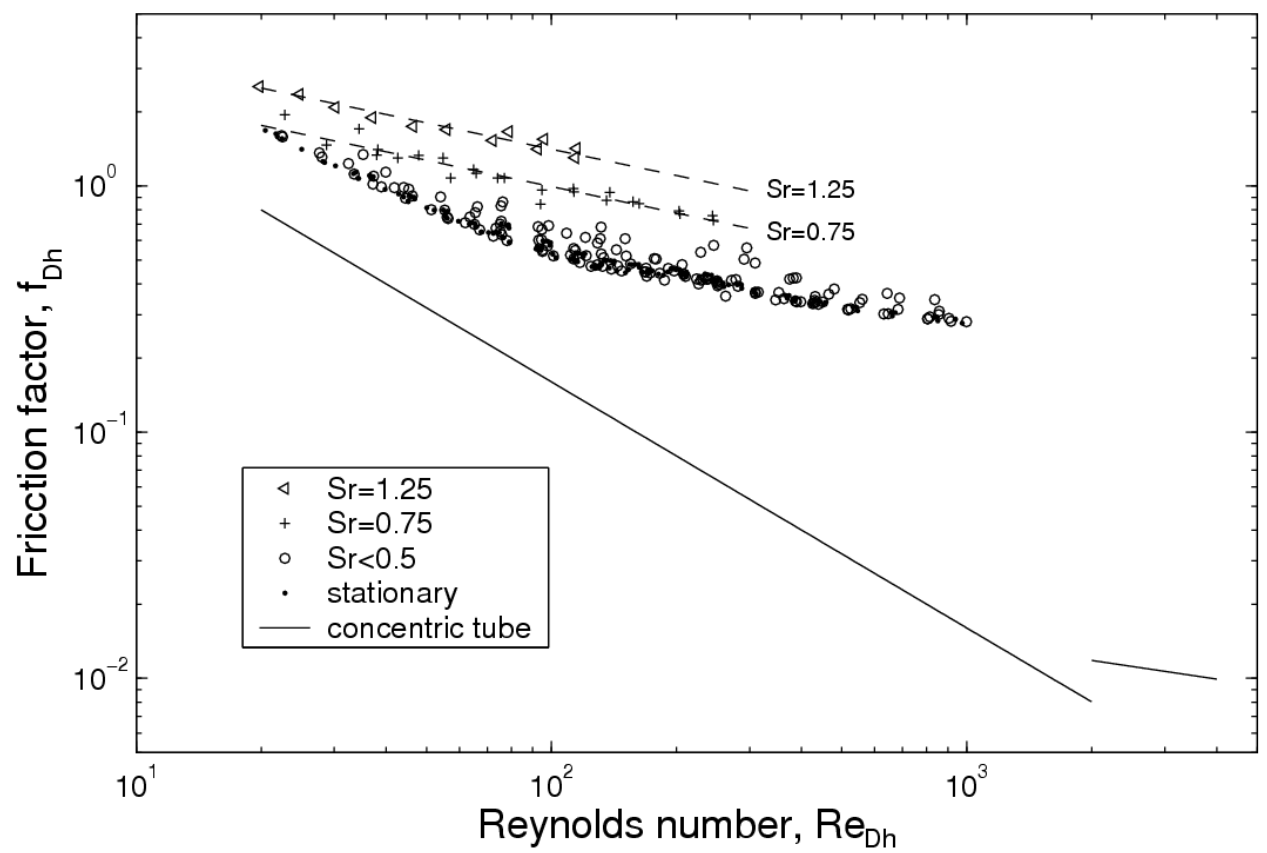

Figure 3. Pressure drop results. Friction factor vs. Reynolds and Strouhal numbers

Friction factor results are compared to the well-known solution of the friction factor in the annular region between two concentric cylinders of diameters 4.5 and $18 \mathrm{~mm}$. The scraping elements produce a significant pressure drop which increases with device speed: at $R e_{D h}=100$ pressure drop is increased by a factor 3 if the insert device is static and it arises to 10 times at Strouhal number 1.6.

\subsection{Heat Transfer Results}

Heat transfer tests under uniform heat flux conditions were carried out in the dynamic reciprocating device. The analysis was focused in the laminar region covering a wide range of flow conditions: Reynolds numbers from 25 to 900, Prandtl numbers from 200 to 800 and Strouhal numbers from 0 (static) to 1.6. Tests were performed at $0.25,0.5,1$ and 2 cycles per second. The amplitude of the scraper movement was $90 \mathrm{~mm}$.

A dimensional analysis shows that Nusselt number may be a function of Reynolds, Prandtl and Strouhal numbers. Fig. 4 shows heat transfer results as a function of Reynolds number for Strouhal numbers above and below 0.25 , which accounts for the clear influence of the scraper frequency on heat transfer.

At Reynolds numbers below 80, heat transfer augmentation depends only on the scraper movement. By changing the scraper frequency from 0.25 to 2 cycles/s, Nusselt number is increased approximately by a factor 3 .

These results show that a dynamic reciprocating scraper produces high heat transfer coefficients in viscous fluids at very low Reynolds numbers. This active enhancement technique can be employed in many practical applications of industrial interest. Moreover, a mechanically assisted heat exchanger which uses this insert device will work all the time under predicted overall heat transfer coefficients, since fouling is avoided. 


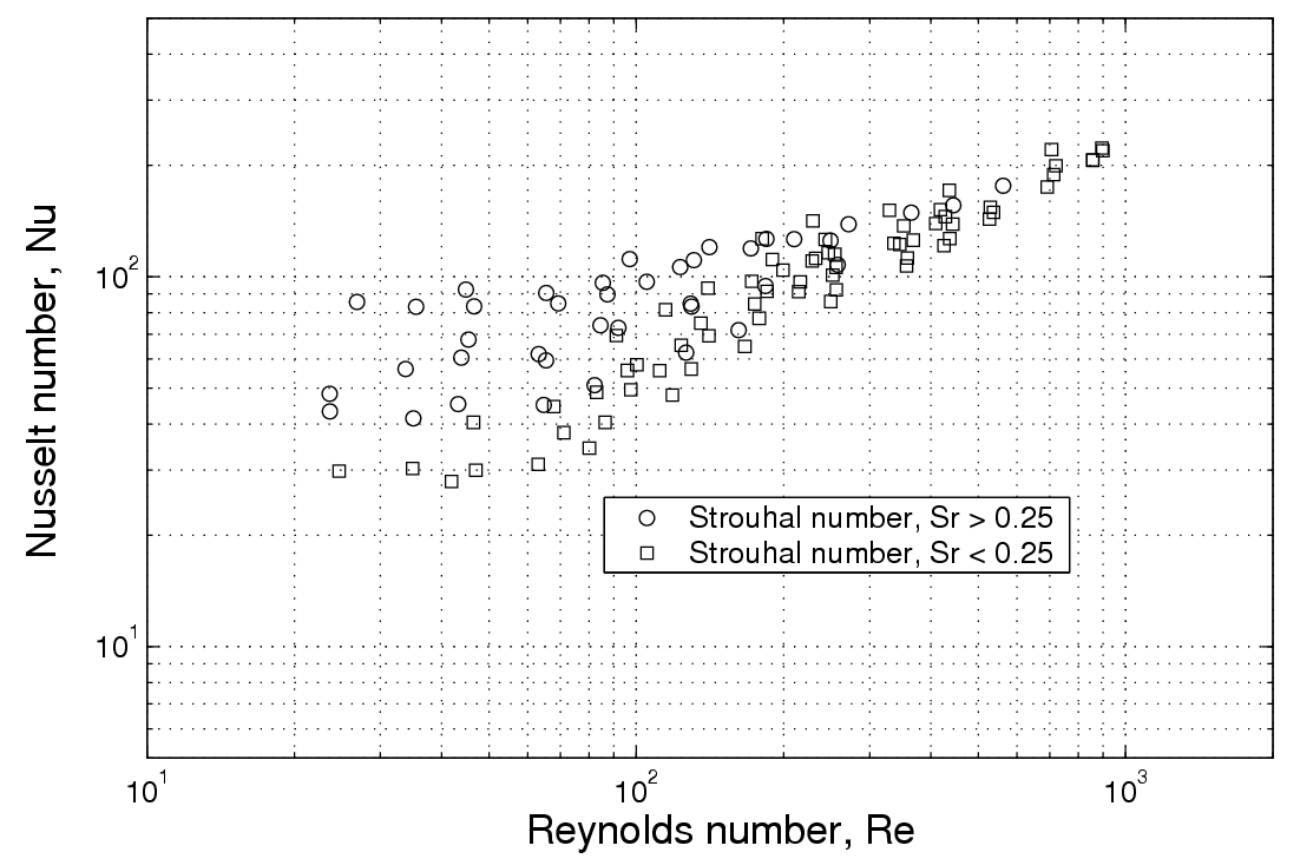

Figure 4. Heat transfer results. Nusselt number vs. Reynolds number at different Strouhal.

At Reynolds numbers between 80 and 500, both Reynolds and Strouhal numbers have influence on heat transfer augmentation. The Reynolds number influence on heat transfer depends on frequency: at 0.25 cycles/s, $N u \propto \mathrm{Re}^{0.7}$ and at 2 cycles/s, $N u \propto \mathrm{Re}^{0.35}$.

Nusselt number results converge at Reynolds number above 500. At $R e=700$, Nusselt number is about 200 and does not depend on the scraping frequency. At these flow conditions, the best option is to move the scraper at the lowest frequency. In applications where fouling tendency is very severe, a faster movement might be considered.

More experimental data are needed in order to develop an experimental correlation for Nusselt number as a function of $\operatorname{Re}$ and $\operatorname{Pr}$ for the quasi-static flow $(S r<0.25)$.

\section{Conclusions}

1. A comprehensive experimental research has been carried out to obtain the thermo-hydraulic behaviour of a dynamic insert device. The analysis covered a wide range of flow conditions: Reynolds numbers from 25 to 900, Prandtl numbers from 200 to 800 and Strouhal numbers from 0 (static) to 1.6.

2. Experiments show that, at Strouhal numbers below 0.25 , the flow can be considered almost stationary. Strouhal number was found to be a good non dimensional parameter to characterize the unsteady flow induced by the insert device.

3. Experiments show that scraping elements produce a significant pressure drop which increases with scraping frequency: at $R e_{D h}=100$ pressure drop is increased a factor 3 if the insert device is static and it arises to 10 times at Strouhal number 1.6. 
4. At Reynolds numbers below 80, heat transfer augmentation depends only on the scraper movement. By changing the scraper frequency from 0.25 to 2 cycles/s, heat transfer is increased by a factor about 3 .

5. Nusselt number results converge at Reynolds numbers above 500: at this Reynolds number, Nusselt number does not depend on the scraper velocity. At these flow conditions, the best option is to move the scraper at the lowest frequency. In applications where fouling tendency is very severe, a faster movement might be considered.

\section{Acknowledgements}

This research has been partially financed by the DPI2003-07783-C02 grant of the "Dirección General de Investigación del Ministerio de Educación y Ciencia de España" and the "HRS Spiratube” company.

\section{References}

[1] R.L. Webb, Principles of Enhanced Heat Transfer, first ed., Wiley Interscience, New York, 1994

[2] A.E. Bergles, ExHFT for fourth generation heat transfer technology, Exp. Therm. Fluid Sci. 26 (2002) 335-344

[3] W. Wang, J.H. Walton, K.L. McCarthy, Flow profiles of power law fluids in scaped surface heat exchanger geometry using MRI, Journal of Food Process Engineering 22 (1999) 11-27

[4] R.De Goede, E.J.De Jong, Heat transfer properties of a scraped-surface heat exhanger in the turbulent flow regime, Chemical Engineering Science, Vol. 48, No. 8, pp.1393-1404, (1993)

[5] K.-H. Sun, D.L. Pyle, A.D. Fitt, C.P. Please, M.J. Baines, N. Hall-Taylor, Numerical study of 2D heat transfer in a scraped surface heat exchanger, Computers \& Fluids 33 (2004) 869-880

[6] Guide to the Expression of Uncertainty in Measurement, first ed., ISBN 92-67-10-188-9, International Organization for Standardization, Switzerland, 1995.

[7] P.G. Vicente, A. Garcia, A. Viedma, Experimental study of mixed convection and pressure drop in helically dimpled tubes for laminar and transition flow, Int. J. Heat Mass Transfer 45 (2002) 5091-5105. 